\title{
Coronavirus disease 2019 (COVID-19): A New Pandemic and its Challenges
}

\author{
Davood Mansury ${ }^{1}$, Sharareh Moghim 1,** \\ ${ }^{1}$ Department of Microbiology, School of Medicine, Isfahan University of Medical Sciences, Isfahan, Iran
}

\begin{abstract}
Emerging of severe acute respiratory syndrome coronavirus 2 (SARS-CoV-2) has caused a worldwide outbreak and a major public health problem. The present review was conducted to provide brief information about the origin, symptoms, transmission, pathogenesis, diagnosis, and treatment of the virus. A search was performed in the databases of PubMed, Scopus, Science Direct, and Google scholar with English keywords including 2019-nCoV, Coronavirus disease 2019 (COVID-19), SARS-CoV-2, and novel coronavirus from December 2019 to 15 March 2020, and the search results were evaluated. Selected studies have shown that the virus may have originated from the bat. It has also been shown that the virus receptor is angiotensin-converting enzyme 2 (ACE2) which is also the SARS virus receptor and is expressed in most human tissues. The most common way of virus transmission was suggested through respiratory droplets and close contact. It is also transmitted by asymptomatic patients, but vertical transmission from mother to fetus has not been confirmed. Real-time reverse transcriptase (RT)-PCR is the gold standard for SARS-CoV-2 detection, but chest computed tomography (CT) can be more sensitive to detect positive cases. Since no effective vaccine or drug for prevention and treatment of this disease has not yet been identified and also because of the high incubation and infection period, easy transmission, and the lack of complete recognition of the characteristics and stability in different environments, the best way to control of COVID-19 is to prevent the spread of the infection in different ways and take seriously personal and public hygiene.
\end{abstract}

Keywords: Coronavirus, COVID-19, SARS-CoV-2, Emerging viruses, Pathogenesis

\section{Introduction}

Coronaviruses are one of the most important pathogens in the human respiratory system. Severe Respiratory Syndrome (SARS) and Middle East Respiratory Syndrome (MERS) have previously been identified as risk factors for general health [1]. In late December 2019, a report was published on pneumonia in a group of patients with unknown cause, possibly related to contact with the seafood market in Wuhan, China [2]. In January 2020, the World Health Organization (WHO) temporarily

\footnotetext{
* Corresponding author:

Dr. Sharareh Moghim, Ph.D

Department of Microbiology, School of Medicine,

Isfahan University of Medical Sciences, Isfahan, Iran

Tel/Fax: +98 3137929038

Email: moghim@med.mui.ac.ir

http://orcid.org/oooo-0002-7134-3145
}

Received: September, 30, 2020

Accepted: November, 11, 2020 named this virus the 2019 novel coronavirus (2019$\mathrm{nCoV}$ ). Later, in February 2020, they officially named it severe acute respiratory syndrome coronavirus 2 (SARS-CoV-2) [3, 4]. The coronaviruses are a class of coated single-stranded RNA viruses that are genetically and serologically subdivided into four subfamilies, including alpha, beta, gamma, and delta. In this regard, most human infections are caused by alpha and beta subfamilies. Phylogenetic analyses show that the etiology of coronavirus disease 2019 (COVID-19), like SARS and MERS, belongs to the 
Table 1. Epidemiological comparison of COVID-19 with MERS and SARS (15 march 2020)

\begin{tabular}{|c|c|c|c|}
\hline Characterization & COVID-19 & SARS & MERS \\
\hline Onset of infection & Wuhan, China & Guangdong, China & Saudi Arabia \\
\hline Year of the outbreak & 2019- Now & $2002-2003$ & 2012 \\
\hline Primary host & Not clear, probably bats & Probably cats and bats & Probably camel \\
\hline $\begin{array}{l}\text { Human-to-human } \\
\text { transmission }\end{array}$ & Yes & Yes & Yes \\
\hline Hospital transfer & Yes & Yes & Yes \\
\hline $\begin{array}{l}\text { Number of countries } \\
\text { involved }\end{array}$ & 216 & 29 & 27 \\
\hline Number of cases * & $50,586,712$ & 8437 & 2494 \\
\hline Mortality rate & $\sim 2.5 \%$ & $11 \%$ & $34.4 \%$ \\
\hline
\end{tabular}

beta-coronavirus and is now known as SARS-CoV2 due to its high genetic similarity to SARS $[1,5,6]$. Reports suggest that the virus has spread to most countries in the world (Table 1) [7-9], and the World Health Organization (WHO) considers it a pandemic [10]. So far, no evidence of mutation has been reported for SARS-CoV-2, probably due to the compatibility of the virus with humans, which binds to its receptor angiotensin-converting enzyme 2 (ACE2) with very high affinity [11]. It is more likely that the SARS virus also mutated during the 2002-2004 epidemics to better bind and replicate to its cellular receptor and increased its pathogenicity [12]. In this regard, it is necessary to investigate clinically isolated viruses with more time and geographical diversity to develop and use appropriate prevention and treatment methods with full knowledge of the characteristics of the virus. The present study was conducted to provide an overview of the origin, symptoms, transmission, pathogenesis, diagnosis, and treatment of this virus.

\section{Source of virus}

Although the source of COVID-19 has not yet been fully clarified, epidemiological studies and pathogen analysis suggest that the southern Chinese seafood market in Wuhan may be an important source of infection. Although the evidenced source of this virus is wild animals, it has not been clarified which animal became infected with the virus and transmitted it to humans [4]. Other studies have suggested that COVID-19 may have originated from a coronavirus with bat origin. Evidence suggests a high degree of ACE2 receptor homology of diversity in animal species (except mice and rats). Thus, these animal species may be considered as intermediate hosts or animal models for COVID-19 infection. Also, these viruses have an open reading frame (ORF) and intact on gene 8 , which is another indicator for coronaviruses with bat origin $[1,13]$. Also, the genomic analysis of viruses isolated from patients has a similarity of $96.2 \%$ to coronaviruses isolated from bats [14]. Nevertheless, the source of the infection has not been completely recognized and more studies are needed in the future in this regard.

\section{Ways of virus transmission}

The main way for transmission of the virus is the transmission of respiratory droplets and close contact with patients suffering from coronary pneumonia. Studies suggest that the pathogen can also be isolated from patients' feces and urine. In infected people, respiratory droplets contain a large number of infectious agents that enter the environment through coughing and sneezing. The spread of respiratory droplets is unlikely without the help of environmental conditions [15]. Rather, the transmission of this virus is more likely to occur in crowded and poorly ventilated public places such as conference rooms, restaurants, stations, public transportation, elevators, and temporary shelters. There are usually two ways for its transmission through content, including direct contact and indirect contact. In the indirect contact, pathogens spread by the source of COVID-19 virus can easily infect the environment and surrounding devices, thereby infecting susceptible individuals [4, 14]. Unlike the SARS virus, the COVID-19 can be transmitted during the incubation period [16]. Analysis of 22 studies suggests that human viruses 
such as SARS, MERS, and human coronavirus $(\mathrm{HCoV})$ can remain active on non-living surfaces such as metal, glass, or plastic for up to 9 days [17]. Also, a study reported the probability of transmitting the infection through the hospital at $41 \%$ from suspected patients [18].

A small number of patients with COVID-19 have reported gastrointestinal symptoms. Also, ACE2 protein is highly expressed in glandular cells in the stomach, duodenum, and rectal epithelium, allowing SARS-CoV-2 to enter cells [19]. Researchers also detected SARS-CoV-2 RNA from patients' feces in Guangdong, Shenzhen, and the United States. According to these researchers, the duration of RNA detection in feces is 1 to 12 days [20]. Most importantly, while some SARS-CoV-2 infected patients experience gastrointestinal symptoms such as diarrhea, it has also been revealed that virus can be isolated from patients' urine, testing stool and urine samples. In this way, it is possible to remove a potential alternative route of transmission, especially through health care staff, patients, and so on. Thus, it is essential to develop some methods to identify different modes of transmission such as stool and urine samples to achieve solutions to inhibit or minimize transmission and develop methods to control the disease [1]. However, isolation of pathogens from feces is not necessarily transmission through the fecal-oral route, but may also be positive through close contact or respiratory infections. There is also no strong evidence for the survival time of SARS-CoV-2 in different environments [4]. However, the use of surface disinfectants such as ethanol, $0.5 \%$ hydrogen peroxide, or $0.1 \%$ sodium hypochlorite for 1 minute can effectively inactivate the virus and play a significant role in controlling the infection [17].

\section{Virus receptors in the human body}

Analysis of recent studies shows that COVID 19 binds to the same SARS receptor as the angiotensinconverting enzyme (ACE2) [13, 21-23]. It has been also shown that the surface protein of COVID 19 (S protein) has 10 times more affinity than the SARS virus for binding to the ACE2 receptor. This result might explain the faster transmission of COVID 19 in humans than the SARS virus [23]. Expression and distribution of ACE2 in the human body may indicate possible routes of infection of COVID-19, such as high expression of ACE2 in cells of various tissues likelung, gastrointestinal tract, heart, kidney, and nasal and oral mucosa [24, 25]. In addition to identifying ACE2 as a receptor, researchers have found downstream ACE 2 as an important target for the type II transmembrane serine proteases (TMPRSS2), which could be considered as a drug design site [11]. In COVID-19, six mutation sites have been found that can affect the characteristics of the virus transmission and the tendency of the virus to bind to cells of various organs. In addition to ACE2, other receptors may be involved in binding the virus to host cells [11].

\section{Pathogenicity}

The mechanism of pathogenicity of COVID-19 is generally unclear and may be affected by various organs. COVID-19 enters cells primarily by binding to human ACE2. Unlike other beta-coronaviruses, primary viral replication is not limited to the upper respiratory mucosal epithelium and may occur in other organs such as the gastrointestinal tract. Some patients also show non-respiratory symptoms such as acute inflammation of the liver, heart damage, kidney failure, and diarrhea $[18,24,26]$. Attacks on various organs result in a complex condition and a variety of clinical manifestations, especially in the early stages of the disease [27]. Patients infected with COVID-19 show higher leukocyte counts, abnormal respiratory findings, and elevated plasma pro-inflammatory cytokine levels [1]. A male case study of a leukopenia patient showed a leukocyte count of $2.91 \times 10^{9} / \mathrm{L}$, of which $70 \%$ were neutrophil. Also, $16 \mathrm{mg} \mathrm{C}$ Reactive Protein (CRP) was observed in the blood that was higher than normal (o-10 mg/l). Increased erythrocyte and D-dimer sedimentation were also observed [28]. The main pathogenesis of COVID-19 infection as a targeted virus of the respiratory system is severe pneumonia, viral RNA in the blood, glassy background turbidity, and acute heart damage in some cases. Increased levels of cytokines and chemokines have been observed in patients infected with COVID-19 including IL1- $\beta$, IL1RA, IL7, IL8, IL9, IL10, basic FGF2, GCSF, GMCSF, IFN $\gamma$, IP10, MCP1, MIP1 $\alpha$, MIP1 $\beta$, PDGFB, TNFa, and VEGFA. Some severe cases admitted to the intensive care unit showed high levels of pro-inflammatory cytokines including IL2, IL7, IL10, GCSF, IP10, MCP1, MIP1a, and TNFa [24]. Cytokine secretion syndrome is a major cause of disease exacerbation and progression. High levels of IL-6 and IL-10 have been observed in patients with 
COVID-19 with increasing the severity of the disease [29]. IL-6 and IL-10 are major cytokines that are consistently elevated in patients with cytokine secretion syndrome. Significant reductions in $\mathrm{CD} 4+\mathrm{T}$ cells and CD8+T cells counts have been observed in COVID-19 patients [6].

\section{Disease symptoms}

Symptoms of COVID-19 manifest after the incubation period (approximately 5.2 days) [13, 16]. The onset of symptoms until death is about 6 to 41 days with a mean period of 14 days. This time depends on the immune system conditions and age of patients [30]. Various studies have reported the main symptoms of the disease as fever, coughing, shortness of breath, fatigue, and muscle pain while others have also reported sputum, headache, hemoptysis, and diarrhea $[22,24,30,31]$. It is of note that there are similarities in symptoms between COVID-19 and beta-coronaviruses such as fever, dry coughing, and shortness of breath [24]. Nevertheless, COVID-19 has some unique clinical characteristics such as lower airway involvement and upper respiratory tract symptoms such as the runny nose, sneezing, and sore throat $[32,33]$.

\section{Laboratory findings}

In a study conducted on 41 patients in Wuhan, China, $63 \%$ of patients with lymphopenia and $37 \%$ of patients with elevated levels of AST enzyme showed an increase in high levels of IL2, IL7, and IL10. Moreover, compared to non- intensive care unit (ICU) patients, ICU patients showed higher levels of IL2, IL7, IL10, GSCF, IP10, MCP1, MIP1A, and TNFa. Data analysis also showed that the likelihood of having lymphopenia, high levels of AST, high levels of Ddimer, and elevated cardiac enzymes were directly associated with the severity of patients and the rate of transfer to ICU [24]. In another study conducted on 123 coronary patients, low levels of $\mathrm{CD} 4+\mathrm{T}$ cells and CD8+ T cells were observed in patients with severe pneumonia, but IL-6 and IL-10 levels were higher in these patients. Thus, it can be stated that the T cells and cytokines can be used as a basis for predicting mild to severe disease [29].

\section{Diagnosis}

In a study conducted on 1,014 patients suspected of COVID-19, RT-PCR tests and CT imaging of the chest were used for the disease diagnosis and $59 \%$ and 88\% positive cases were reported, respectively. Using RT-PCR as a reference, the sensitivity of CT imaging was calculated at $97 \%$. In this study, serial methods of these two tests showed that in 60 to $90 \%$ of patients, the initial CT test was positive before positive RT-PCR. Also, in the follow-up of $42 \%$ of patients, a CT scan of the normal chest before RT- Chest CT was negative. Thus, chest CT had a higher sensitivity (not specificity) for diagnosing COVID-19 compared to RT-PCR from swab samples in the Chinese epidemic area [34]. In another research, 49 out of 51 patients with COVID 19, confirmed by molecular tests, had a positive CT test (96.1\%). For this reason, this study recommended that CT imaging may be useful as a standard method for the rapid diagnosis of COVID 19 to optimize patient management (28). In another study, the sensitivity of CT imaging was reported to be $95 \%$ based on clinical findings. Also, it was found that CT imaging could reduce cases of false-negative nucleic acid testing [22]. However, the final confirmation of patients includes RT-PCR real-time PCR or sequencing of viral genes in respiratory or blood samples [16].

\section{Treatment and prevention}

There is no specific antiviral drug or vaccine against COVID 19 infection for possible treatment and prevention in humans. The only available option is to use broad-spectrum antiviral drugs such as nucleoside analogs and HIV-protease inhibitors, which can weaken virus infection until a specific antivirus is available $[35,36]$. Some of the antiviral drugs used to treat these patients include oseltamivir, lopinavir, ganciclovir, and ritonavir [37]. Another study reported that the broad-spectrum antiviral drugs of Remdesivir and chloroquine were very effective in controlling COVID-19 infection in vitro [26]. Moreover, a laboratory study and a clinical study showed that Remdesivir (which is a new nucleotide analog) and adenosine analog (which acts as a viral protein inhibitor) improved one patient [38, 39]. The Chinese National Health Commission states that Tocilizumab (Actemra) can treat COVID-19 patients who have severe lung damage and high levels of IL-6. This drug applies its effect by inhibiting high levels of protein interleukin-6, which can cause inflammation [40]. Although the treatment of some cases with interferon inhalation showed no clinical effect, it worsened the condition as pulmonary turbidity progresses [28]. 
However, more studies are needed to identify new therapeutic drugs to treat COVID-19 infection. Many scientists are currently trying to develop a non-human model for studying COVID-19 infection for rapid treatment and testing of potential vaccines, as well as providing a better understanding of virus-host interaction [1].

\section{Iranian experiences at a glance}

Between 20 February 2020 and 2 April 2020, a hospital based-study study was conducted in one of the first and largest hospital that was specifically designated for the hospitalization of individuals with suspected COVID-19 in Tehran (Capital of Iran). Their findings showed that of 1,061 suspected patients, 570 patients had RT-PCR positive results and confirmed as a COVID-19 infection. Among them, 15.6\% patients died (with a median age of 64 years), and $4.4 \%$ were referred to the ICUs. The median (IQR) age of these patients was 56.5 (45-66) years and approximately 65\% were male [41]. Another study in above mentioned hospital 231 suspected cases of COVID-19 were studied during two weeks. Of which 31.2\% were confirmed as a COVID-19 cases by RT-PCR and admitted to ICU with different level of acute respiratory distress syndrome (ARDS). In overall, 25\% of ARDS cases were died over two weeks. Different therapeutic regimens were employed for these patients including the use of oxygen therapy, supplementation (vitamin D3, thiamine, and selenium), steroid therapy, immunoglobulin therapy, and interferon beta-1a and Ribavirin combination [42]. Ghanbari on forecasting the spread of the COVID-19 in Iran, predict that the second wave will be more challenging and is predicated to happen between August and December 2020 [43].

\section{Conclusion}

Based on the studies and experiences mentioned in this article, the following recommendations are presented: 1) preventing and controlling the infection, observing personal and public health, quarantining suspicious and sick people, and not traveling and 2) using CT scan technique to diagnose patients, followed by using molecular tests for confirmation. In general, the diagnosis of the virus in many organs complicates the determination of the source and route of transmission of the new coronary pneumonia and increases the risk of transmission. Major gaps in our knowledge on the origin, epidemiology, and duration of human transmission and clinical spectrum of the disease make it necessary to conduct more studies in the future.

\section{Authors Contribution}

All authors contributed equally in data collection and drafting of the manuscript. Also, all authors approved the final version of the manuscript.

\section{Conflict of Interests}

The authors do not have any conflict of interest to disclose.

\section{Ethical declarations \\ Not applicable.}

\section{Financial Support}

None.

\section{References}

1. Rothan HA, Byrareddy SN. The epidemiology and pathogenesis of coronavirus disease (COVID-19) outbreak. J Autoimmun. 2020; 109:102433.

2. Bogoch, II, Watts A, Thomas-Bachli A, Huber C, Kraemer MUG, Khan K. Pneumonia of unknown aetiology in Wuhan, China: potential for international spread via commercial air travel. J Travel Med. 2020; 27(2):taaaoo8.

3. Sun P, Lu X, Xu C, Sun W, Pan B. Understanding of COVID-19 based on current evidence. J Med Virol. 2020; 92(6):548-51.

4. Yang H, Duan G. Analysis on the epidemic factors for the corona virus disease. Zhonghua yu Fang yi xue za zhi [Chi J Prev Med]. 2020; 54:(6):608-613.

5. Jin Y, Yang H, Ji W, Wu W, Chen S, Zhang W, et al. Virology, Epidemiology, Pathogenesis, and Control of COVID-19. Viruses. 2020; $12(4): 372$.

6. Fani M, Teimoori A, Ghafari Sh. Comparison of the COVID2019 (SARS-CoV-2) pathogenesis with SARS-CoV and MERS$\mathrm{CoV}$ infections. Future Virol. 2020. [In press]. https://dx.doi.org/10.2217\%2Ffvl-2020-0050

7. Arabi YM, Murthy S, Webb S. COVID-19: a novel coronavirus and a novel challenge for critical care. Intensive Care Med. 2020; 46(5):833-6.

8. Park M, Thwaites RS, Openshaw PJ. COVID-19: lessons from SARS and MERS. Eur J Immunol. 2020; 5O(3):308. 9. 15 R.

9. COVID-19 coronavirus pandemic. Retrieved 8 November 2020. Availible at: https://www.worldometers.info/coronavirus.

10. Cucinotta D, Vanelli M. WHO Declares COVID-19 a Pandemic. Acta Biomed. 2020;91(1):157-160.

11. Mohammadpour S, Torshizi Esfahani A, Halaji M, Lak M, Ranjbar R. An updated review of the association of host genetic factors with susceptibility and resistance to COVID-19. J Cell Physiol. 2020. [In press]. https://doi:10.1002/jcp.29868.

12. Perlman S. Another Decade, Another Coronavirus. N Engl J Med. 2020; 382(8):760-2. 
13. Wan Y, Shang J, Graham R, Baric RS, Li F. Receptor Recognition by the Novel Coronavirus from Wuhan: an Analysis Based on Decade-Long Structural Studies of SARS Coronavirus. J Virol. 2020; 94(7). eo0127-20

14. Zhou P, Yang XL, Wang XG, Hu B, Zhang L, Zhang W, et al. A pneumonia outbreak associated with a new coronavirus of probable bat origin. Nature. 2020; 579(7798):270-3.

15. Halaji M, Farahani A, Ranjbar R, Heiat M, Dehkordi FS. Emerging coronaviruses: first SARS, second MERS and third SARS-CoV-2: epidemiological updates of COVID-19. Infez Med. 2020; 28(suppl 1):6-17.

16. Jin YH, Cai L, Cheng ZS, Cheng H, Deng T, Fan YP, etal. A rapid advice guideline for the diagnosis and treatment of 2019 novel coronavirus (2019-nCoV) infected pneumonia (standard version). Mil Med Res. 2020; 7(1):4.

17. Kampf G, Todt D, Pfaender S, Steinmann E. Persistence of coronaviruses on inanimate surfaces and their inactivation with biocidal agents. J Hosp Infect. 2020; 104(3):246-51.

18. Wang D, Hu B, Hu C, Zhu F, Liu X, Zhang J, et al. Clinical Characteristics of 138 Hospitalized Patients With 2019 Novel Coronavirus-Infected Pneumonia in Wuhan, China. Jama. 2020; 323(11):1061-9.

19. Zhang H, Kang Z, Gong H, Xu D, Wang J, Li Z, et al. Digestive system is a potential route of COVID-19: an analysis of single-cell coexpression pattern of key proteins in viral entry process. Gut. 2020; 69(6):1010-18.

20. Yeo C, Kaushal S, Yeo D. Enteric involvement of coronaviruses: is faecal-oral transmission of SARS-CoV-2 possible? Lancet Gastroenterol Hepatol. 2020; 5(4):335-7.

21. Ge XY, Li JL, Yang XL, Chmura AA, Zhu G, Epstein JH, et al. Isolation and characterization of a bat SARS-like coronavirus that uses the ACE2 receptor. Nature. 2013; 503(7477):535-8.

22. Ren LL, Wang YM, Wu ZQ, Xiang ZC, Guo L, Xu T, et al. Identification of a novel coronavirus causing severe pneumonia in human: a descriptive study. Chin Med J (Engl). 2020; 133(9):101524.

23. Wrapp D, Wang N, Corbett KS, Goldsmith JA, Hsieh CL, Abiona O, et al. Cryo-EM structure of the 2019-nCoV spike in the prefusion conformation. Science. 2020; 367(6483):1260-3.

24. Huang C, Wang Y, Li X, Ren L, Zhao J, Hu Y, et al. Clinical features of patients infected with 2019 novel coronavirus in Wuhan, China. Lancet. 2020; 395(10223):497-506.

25. Zou X, Chen K, Zou J, Han P, Hao J, Han Z. Single-cell RNAseq data analysis on the receptor ACE2 expression reveals the potential risk of different human organs vulnerable to 2019-nCoV infection. Front Med. 2020; 14(2):185-92.

26. Cheng Y, Luo R, Wang K, Zhang M, Wang Z, Dong L, et al. Kidney disease is associated with in-hospital death of patients with COVID-19. Kidney Int. 2020; 97(5):829-38.

27. Guan W-j, Ni Z-y, Hu Y, Liang W-h, Ou C-q, He J-x, et al. Clinical Characteristics of Coronavirus Disease 2019 in China. N Engl J Med. 2020; 382(18):1708-20.

28. Lei J, Li J, Li X, Qi X. CT Imaging of the 2019 Novel Coronavirus (2019-nCoV) Pneumonia. Radiology. 2020; 295(1):18.

29. Wan S, Yi Q, Fan S, Lv J, Zhang X, Guo L, et al. Characteristics of lymphocyte subsets and cytokines in peripheral blood of 123 hospitalized patients with 2019 novel coronavirus pneumonia (NCP). MedRxiv. 2020. [Preprint]. https://doi.org/10.1101/2020.02.10.20021832

30. Wang W, Tang J, Wei F. Updated understanding of the outbreak of 2019 novel coronavirus (2019-nCoV) in Wuhan, China. J Med Virol. 2020; 92(4):441-7.

31. Carlos WG, Dela Cruz CS, Cao B, Pasnick S, Jamil S. Novel Wuhan (2019-nCoV) Coronavirus. Am J Respir Crit Care Med. 2020; 201(4):P7-p8.

32. Assiri A, Al-Tawfiq JA, Al-Rabeeah AA, Al-Rabiah FA, AlHajjar S, Al-Barrak A, et al. Epidemiological, demographic, and clinical characteristics of 47 cases of Middle East respiratory syndrome coronavirus disease from Saudi Arabia: a descriptive study. Lancet Infect Dis. 2013; 13(9):752-61.

33. Lee N, Hui D, Wu A, Chan P, Cameron P, Joynt GM, et al. A major outbreak of severe acute respiratory syndrome in Hong Kong. N Engl J Med. 2003; 348(20):1986-94.

34. Ai T, Yang Z, Hou H, Zhan C, Chen C, Lv W, et al. Correlation of Chest CT and RT-PCR Testing for Coronavirus Disease 2019 (COVID-19) in China: A Report of 1014 Cases. Radiology. 2020; 296(2):E32-E40.

35. Lu H. Drug treatment options for the 2019-new coronavirus (2019-nCoV). Biosci Trends. 2020; 14(1):69-71.

36. Mirzaie A, Halaji M, Dehkordi FS, Ranjbar R, Noorbazargan H. A narrative literature review on traditional medicine options for treatment of corona virus disease 2019 (COVID-19). Complement Ther Clin Pract. 2020; 40:101214.

37. Chen N, Zhou M, Dong X, Qu J, Gong F, Han Y, et al. Epidemiological and clinical characteristics of 99 cases of 2019 novel coronavirus pneumonia in Wuhan, China: a descriptive study. Lancet. 2020; 395(10223):507-13.

38. Holshue ML, DeBolt C, Lindquist S, Lofy KH, Wiesman J, Bruce H, et al. First Case of 2019 Novel Coronavirus in the United States. N Engl J Med. 2020; 382(10):929-36.

39. Wang M, Cao R, Zhang L, Yang X, Liu J, Xu M, et al. Remdesivir and chloroquine effectively inhibit the recently emerged novel coronavirus (2019-nCoV) in vitro. Cell Res. 2020; 30(3):269-71.

40. Xu X, Han M, Li T, Sun W, Wang D, Fu B, et al. Effective treatment of severe COVID-19 patients with tocilizumab. Proc Natl Acad Sci U S A. 2020; $117(20): 10970-5$.

41. Pourabdollah Toutkaboni M, Askari E, Khalili N, Tabarsi P, Jamaati H, Velayati AA, et al. Demographics, laboratory parameters and outcomes of 1061 patients with coronavirus disease 2019: a report from Tehran, Iran. New Microbes New Infect. 2020; 38:100777.

42. Jamaati H, Dastan F, Tabarsi P, Marjani M, Saffaei A, Hashemian SM. A Fourteen-day Experience with Coronavirus Disease 2019 (COVID-19) Induced Acute Respiratory Distress Syndrome (ARDS): An Iranian Treatment Protocol. Iran J Pharm Res. 2020; 19(1):31-6.

43. Ghanbari B. On forecasting the spread of the COVID-19 in Iran: the second wave. Chaos Solitons Fractals. 2020; 140:110176. 